\title{
Lung Cancer Imaging: Screening Result and Nodule Management
}

\author{
Susanna Guerrini ${ }^{1, * \mathbb{C}}$, Davide Del Roscio ${ }^{2}$, Matteo Zanoni ${ }^{2}$, Paolo Cameli ${ }^{3}$, Elena Bargagli ${ }^{3}$, Luca Volterrani ${ }^{2}$, \\ Maria Antonietta Mazzei ${ }^{2,4}$ (1) and Luca Luzzi ${ }^{5}$
}

check for updates

Citation: Guerrini, S.; Del Roscio, D.; Zanoni, M.; Cameli, P.; Bargagli, E.; Volterrani, L.; Mazzei, M.A.; Luzzi, L. Lung Cancer Imaging: Screening Result and Nodule Management. Int. J. Environ. Res. Public Health 2022, 19, 2460. https://doi.org/10.3390/ ijerph19042460

Academic Editor: Oliver Faust

Received: 28 December 2021

Accepted: 14 February 2022

Published: 21 February 2022

Publisher's Note: MDPI stays neutral with regard to jurisdictional claims in published maps and institutional affiliations.

Copyright: (C) 2022 by the authors. Licensee MDPI, Basel, Switzerland. This article is an open access article distributed under the terms and conditions of the Creative Commons Attribution (CC BY) license (https:// creativecommons.org/licenses/by/ $4.0 /)$.
1 Unit of Diagnostic Imaging, Department of Radiological Sciences, Azienda Ospedaliero-Universitaria Senese, University of Siena, 53100 Siena, Italy

2 Unit of Diagnostic Imaging, Department of Medical, Surgical and Neuro Sciences and of Radiological Sciences, Azienda Ospedaliero-Universitaria Senese, University of Siena, 53100 Siena, Italy; davide.delroscio90@gmail.com (D.D.R.); matteo.zanoni.91@gmail.com (M.Z.); luca.volterrani@unisi.it (L.V.); mariaantonietta.mazzei@unisi.it (M.A.M.)

3 Respiratory Diseases Unit, Department of Medical, Surgical and Neuro Sciences, Azienda Ospedaliero-Universitaria Senese, University of Siena, 53100 Siena, Italy; cameli3@student.unisi.it (P.C.); bargagli2@unisi.it (E.B.)

4 Italian Society of Medical and Interventional Radiology (SIRM), SIRM Foundation, 20122 Milan, Italy

5 Lung Transplant Unit, Department of Medical, Surgical and Neuro Sciences, Azienda Ospedaliero-Universitaria Senese, University of Siena, 53100 Siena, Italy; dr.luca.luzzi@gmail.com

* Correspondence: guerrinisus@gmail.com; Tel.: +39-327-351-2629

\begin{abstract}
Background: Lung cancer (LC) represents the main cause of cancer-related deaths worldwide, especially because the majority of patients present with an advanced stage of the disease at the time of diagnosis. This systematic review describes the evidence behind screening results and the current guidelines available to manage lung nodules. Methods: This review was guided by the Preferred Reporting Items for Systematic Reviews and Meta-analyses (PRISMA) guidelines. The following electronic databases were searched: PubMed, EMBASE, and the Web of Science. Results: Five studies were included in the systematic review. The study cohort included 46,364 patients, and, in this case series, LC was detected in 9028 patients. Among the patients with detected LC, 1261 died of lung cancer, 3153 died of other types of cancers and 4614 died of other causes. Conclusions: This systematic review validates the use of CT in LC screening follow-ups, and bids for future integration and implementation of nodule management protocols to improve LC screening, avoid missed cancers and to reduce the number of unnecessary investigations.
\end{abstract}

Keywords: lung cancer; prevention; health education; MDCT; lung screening; lung nodule management

\section{Introduction}

Lung cancer (LC) represents the main cause of cancer-related deaths worldwide, especially because the majority of patients present with an advanced stage of the disease at the time of diagnosis [1,2]. Smoking habits and asbestos exposure are still the main risk factors; moreover, smoking prevalence is going to rise in the coming years [3-7]. For these reasons, mass screening of high-risk patients has been introduced in most countries, with the aim of reducing LC mortality. This seems to be potentially beneficial; however, the frequent identification of early stage cancers could lead to the over diagnosis and unnecessary treatment of early lesions that would potentially never become advanced cancers [8]. To address this issue, in Europe and in the US, many multicenter trials were instituted [9-13] to investigate whether screening using multidetector computed tomography (MDCT) would contribute to the reduction in LC mortality [14]. MDCT, with its widespread use and the possibility to use low-dose CT (LDCT), dual-energy CT (DECT) and functional acquisitions, such as CT perfusion (CTp), allows the detection and characterization of early stage LC [15-18].

Lung cancer can present as solid, part-solid or ground-glass nodules $[19,20]$. Sometimes, LC grows near cystic airspaces, as thickening of the wall of a bulla, or present as a 
mass at the first diagnosis [21]. New-generation CT scanners allow the detection of pulmonary lesions, not absolutely malignant, with a prevalence of about $50 \%$, which imposes a tight follow-up, both in screening and diagnostic protocols [22].

For these reasons, nodule management guidelines are necessary to advise on how to manage early detected lesions that need close follow-ups, to correctly identify lesions with a high malignant potential, and to reduce the number of unnecessary examinations or surgical excisions [19].

The purpose of screening is to detect treatable lesions before they become clinically evident, and to address the management of pre-invasive nodular lesions, thereby reducing patient mortality and over-treatment [23].

The aim of this systematic review is to describe the evidence behind screening results and the current guidelines available to manage lung nodules, as well as the indications and appropriate timing of surveillance.

\section{Materials and Methods}

\subsection{Publication Search}

This systematic review was conducted according to the Preferred Reporting Items for Systematic Reviews and Meta-analyses (PRISMA) guidelines.

To find studies to include in this systematic review, we searched the PubMed, EMBASE, and Web of Science electronic databases for articles, using the terms "lung cancer", "lung carcinoma", "imaging", "solitary pulmonary nodules", "lung nodule management", "pulmonary screening", "lung nodules", "computed tomography", "lung cancer screening result", and "lung cancer guidelines". We scrutinized studies published from January 2010 to January 2020, which had been published in English and had been conducted on humans. We also performed manual retrieval to avoid missing important studies. Only full-text articles were included.

\subsection{Inclusion and Exclusion Criteria}

Inclusion criteria were as follows: (1) LC histopathologically or cytologically proven, (2) CT image confirming lung lesion.

Studies were excluded from the analysis for (1) lack of CT imaging or histopathological/cytological results confirming LC; (2) cases of duplicate or overlapping data with other studies; (3) articles were abstracts, case reports, comments; (4) English full-text article was not available.

We evaluated the title and the abstract when the title suggested that the study met the inclusion criteria. If the abstract was relevant, the articles' full versions were read by two of the authors. Disagreements were resolved by a combined full article review and by consensus between the authors.

\subsection{Data Extraction}

Data were extracted independently by two co-authors and discrepancies were resolved by consensus. The following information was considered valid for the analysis: year of publication, country of origin, the number of included patients, age, sex, cause of death and smoking status.

Simultaneously, recent guidelines for monitoring lung nodules to compare nodule timing of surveillance, according to frequent imaging findings, were evaluated, including the following: ground-glass (GG) nodules, solid nodules, and part-solid (PS) nodules. Nodule multiplicity, growth rate, location, size and morphology were also evaluated.

\section{Results}

\subsection{Included Studies}

Our literature search yielded 653 citations. Forty non-duplicated records were eligible for full-text screening, and were examined in detail. Five studies were included in the 
screening study. A flowchart of the literature search and study selection is shown in Figure 1, and the results are summarized in Table 1.

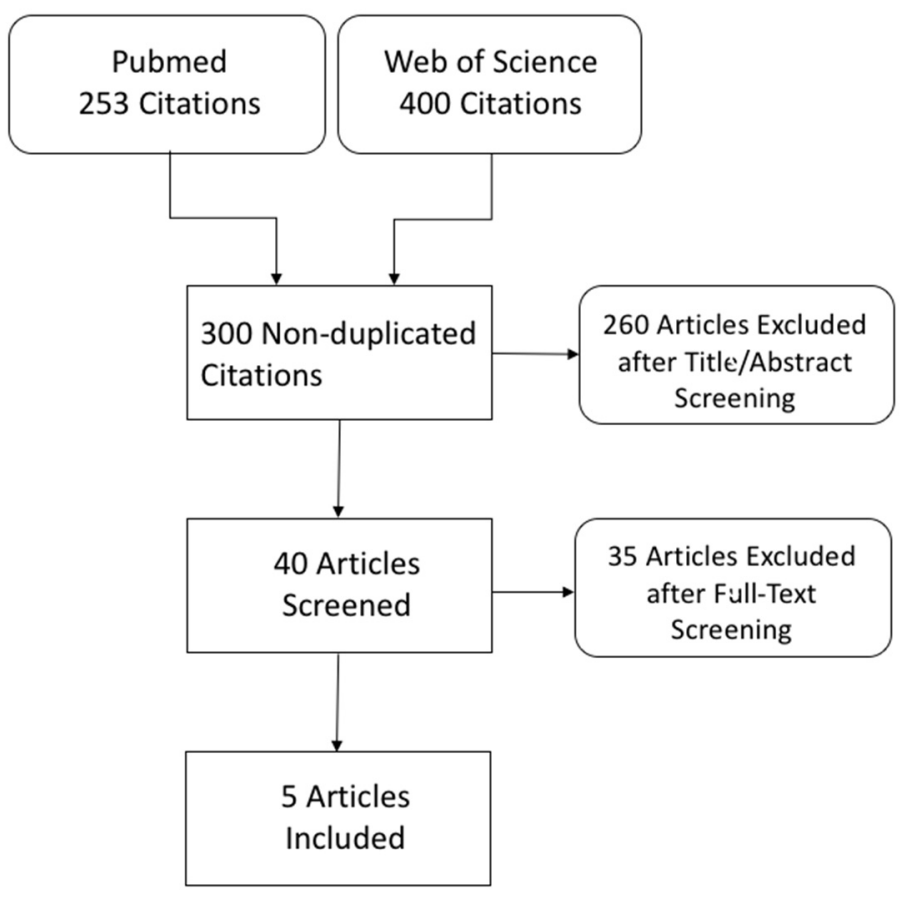

Figure 1. Flowchart of the literature search and study selection.

Table 1. Screening study results.

\begin{tabular}{cccccc}
\hline & $\begin{array}{c}\text { De Koning } \\
\text { 2020 [13] }\end{array}$ & $\begin{array}{c}\text { Infante } \\
\text { 2017 [12] }\end{array}$ & $\begin{array}{c}\text { Infante } \\
\text { 2015 [9] }\end{array}$ & $\begin{array}{c}\text { Horeweg } \\
\text { 2014 [10] }\end{array}$ & $\begin{array}{c}\text { Aberle } \\
\text { 2011 [11] }\end{array}$ \\
\hline Mean Age & 58 yo & 61 yo & 64 yo & 58 yo & NR \\
Male Sex & All & 2890 & NR & 5999 & 15,770 \\
Smoking status * & All & 2344 & 714 & 3959 & 12,862 \\
Mean p/y & 38 & 40 & 47.3 & 38 & NR \\
\hline Patients & 6583 & 3640 & 1264 & 7155 & 27,722
\end{tabular}

* Current smoker was defined as a person who had smoked cigarettes during the last 2 weeks. ${ }^{* *}$ Calculated by multiplying the number of packs of cigarettes smoked per day by the number of years the person had smoked. Yo = year old; NR = not reported. The studies come from different countries, the largest from the United States $[11,13]$ and others from Europe, including Italy $[9,12]$ and The Netherlands [10]. All articles are randomized trials, 3 with a control arm.

For lung nodule guidelines, the evaluation of four articles was included [19,24-26]. All the articles report predictors of malignancy, nodule morphology and size. Comparisons between the guideline recommendations for nodule management are reported in Tables 2 and 3.

\subsection{Patient Characteristics for Screening Results}

The study cohort included 46,364 patients. In this case series, LC was detected in 9028 patients. The following clinical stages were reported in 1865 patients in total: stage IA $(647,34.69 \%)$, stage IB $(174,9.32 \%)$, stage II $(262,14.04 \%)$, stage III $(334,17.90 \%)$, stage IV $(345,18.49 \%)$, and unknown $(103,5.52 \%)$. A total of $149 / 1865$ (7.98\%) patients had NSCLC, $844 / 1865(45.25 \%)$ had adenocarcinoma, 404/1865 (21.66\%) had squamous cell carcinoma, $133 / 1865(7.13 \%)$ had small-cell carcinoma, and 335/1865 (17.96\%) had another type of lung cancer (unknown). Among the patients with detected LC, in a follow-up period ranging from 5 to 10 years, 1261 patients died of lung cancer, 3153 patients died of other types of cancer, and 4614 patients died of other causes. 
Table 2. Comparison of current guidelines for solid nodule management [27].

\begin{tabular}{|c|c|c|c|c|}
\hline $\begin{array}{l}\text { Nodule } \\
\text { Dimensions }\end{array}$ & $\begin{array}{l}\text { The Fleischner } \\
\text { Society [19] }\end{array}$ & $\begin{array}{c}\text { American } \\
\text { College of Chest Physicians [24] }\end{array}$ & $\begin{array}{l}\text { British Thoracic } \\
\text { Society [25] }\end{array}$ & $\begin{array}{c}\text { Lung CT Screening } \\
\text { Reporting and } \\
\text { Data System *[26] }\end{array}$ \\
\hline$<6 \mathrm{~mm}$ & $\begin{array}{l}\text { LR, no FU } \\
\text { HR, } 12 \text { mo FU }\end{array}$ & $\begin{array}{c}\mathrm{LR}, \leq 4 \mathrm{~mm} \text { no FU } \\
\mathrm{LR},>4-6 \mathrm{~mm} \text { or } \mathrm{HR}, \leq 4 \mathrm{~mm}, \\
12 \mathrm{mo} \text { FUHR, }>4-6 \mathrm{~mm}, \\
6-12 \mathrm{mo} \text { FU }\end{array}$ & $\begin{array}{l}<5 \mathrm{~mm}, \text { no FU5-6 mm, } \\
12-24 \mathrm{mo} \mathrm{FU}\end{array}$ & $<6$ mm, AS (cat 2) \\
\hline$\geq 6 \mathrm{~mm}$ to $8 \mathrm{~mm}$ & $\begin{array}{l}\text { LR and HR, } \\
\text { 6-12 mo FU, then } \\
\text { re-evaluate }\end{array}$ & $\begin{array}{l}\text { LR, 6-12 mo FU } \\
\text { HR, 3-6 mo FU }\end{array}$ & $3 \mathrm{mo} F U$ then $12 \mathrm{mo} \mathrm{FU}$ & $\begin{array}{c}\geq 6 \mathrm{~mm} \text { or new nodules } \\
4-6 \mathrm{~mm}, 6 \mathrm{mo} \text { LDCT } \\
\text { (cat } 3)\end{array}$ \\
\hline$\geq 8 \mathrm{~mm}$ & $\begin{array}{l}\mathrm{CT} \text { or } \mathrm{PET} / \mathrm{CT} \\
\text { at } 3 \mathrm{mo}\end{array}$ & $\begin{array}{c}<5 \% \text { risk, } 3 \text { mo FU; } \\
5-65 \% \text { risk, PET } / \mathrm{CT} \\
\text { and / or biopsy; } \\
>65 \% \text { risk, treatment }\end{array}$ & $\begin{array}{l}<10 \% \text { risk, surveillance; } \\
>10 \% \text { risk, } \mathrm{PET} / \mathrm{CT} \text { or } \\
\text { consider resection }\end{array}$ & $\begin{array}{c}8-15 \mathrm{~mm} \\
3 \mathrm{mo} \text { LDCT }(\text { cat } 4 \mathrm{~A}) \\
>15 \mathrm{~mm}(\text { cat } 4 \mathrm{~B})\end{array}$ \\
\hline
\end{tabular}

${ }^{*}$ Lung-RADS ${ }^{\circledR}$ version 1.1; assessment categories release date: 2019. High-risk factors include older age, heavy smoking, larger nodule size, irregular or spiculated margins, and upper lobe location. $\mathrm{HR}=$ high risk; $\mathrm{LR}=$ low risk $\mathrm{mo}=$ months; $\mathrm{FU}=$ follow-up; $\mathrm{AS}$ = annual screening; cat = category; $\mathrm{LDCT}=$ low-dose computed tomography.

Table 3. Comparison of current guidelines for ground-glass and part-solid nodule management [27].

\begin{tabular}{|c|c|c|c|c|}
\hline $\begin{array}{c}\text { Nodule } \\
\text { Dimensions }\end{array}$ & $\begin{array}{l}\text { The Fleischner } \\
\text { Society [19] }\end{array}$ & $\begin{array}{c}\text { American } \\
\text { College of Chest Physicians [24] }\end{array}$ & $\begin{array}{c}\text { British } \\
\text { Thoracic } \\
\text { Society [25] }\end{array}$ & $\begin{array}{l}\text { Lung CT Screening } \\
\text { Reporting and } \\
\text { Data System * }{ }^{[26]}\end{array}$ \\
\hline$<6 \mathrm{~mm}$ & $\begin{array}{l}<6 \mathrm{~mm}, \mathrm{GG} \text { or PS, no FU; } \\
\text { if multiple, 3-6 mo LDCT FU }\end{array}$ & $<6 \mathrm{~mm}, \mathrm{GG}, \mathrm{no} \mathrm{FU}$ & $<5 \mathrm{~mm}$, no FU & $\begin{array}{c}30 \mathrm{~mm} \text { or more, GG, } \\
\text { AS (cat 2) } \\
6 \mathrm{~mm}, \mathrm{PS}, \mathrm{AS} \text { (cat 2) } \\
\text { if new } 6 \text { mo LDCT } \\
\text { (cat 3) }\end{array}$ \\
\hline $\begin{array}{l}\geq 6 \mathrm{~mm} \text { to } \\
8 \mathrm{~mm}\end{array}$ & $\begin{array}{l}\geq 6 \text { mm, GG, } 6-12 \text { mo FU; } \\
\text { PS, 3-6 mo FUIf multiple, } \\
\text { 3-6 mo FU }\end{array}$ & $\begin{array}{c}\geq 6 \mathrm{~mm} \mathrm{GG}, 12 \mathrm{mo} \mathrm{FU} ; \\
\mathrm{PS}, \leq 8 \mathrm{~mm}, 3,12 \text {, and } 24 \mathrm{mo} F U\end{array}$ & $\begin{array}{l}\geq 5 \mathrm{~mm}, 3-\mathrm{mo} \\
\text { LDCT than } \\
\text { re-evaluate }\end{array}$ & $\begin{array}{c}\geq 30 \mathrm{~mm}, \mathrm{GG} \text { or new } \\
6 \text { mo LDCT (cat } 3) \\
6-8 \mathrm{~mm}, \text { PS, } 3 \text { mo } \\
\text { LDCT (cat } 4 \mathrm{~A})\end{array}$ \\
\hline$\geq 8 \mathrm{~mm}$ & / & If solid, 3 mo FU & / & $\geq 8 \mathrm{~mm}, \mathrm{PS},($ cat $4 \mathrm{~B})$ \\
\hline
\end{tabular}

\section{Discussion}

All the evaluated studies agree with the importance of CT/LDCT screening in reducing LC mortality, which was reduced by a percentage of approximatively $20 \%$ in a screening follow-up period of about 10 years. In the de Koning et al. trial, involving high-risk patients (current smokers), there was an increase in LC diagnoses among patients who underwent CT screening when compared with patients who did not adhere to the screening program [13]. In the National Lung Screening Trial (NLST) by Aberle et al., the reduction in mortality of patients who underwent LDCT screening was assessed in comparison with radiography. Even though LDCT reported a high rate of false positive results, it does not seem to be deleterious, considering the decrease in the LC mortality rate [11]. In the DANTE trial (Infante et al., 2015), the false positives and stage I lung cancer rates are comparable with NLST; however, the authors imposed a lower age limit of 60 years to maximize the efficiency of screening [9] compared to other randomized LDCT screening trials [28-30]. Infante et al. (2017) reported an overall mortality reduction of $11 \%$ at the 8-year follow-up, which is no different from the NLST trial, if compared with the small number of participants, and with an increased reduction after the 4-year follow-up [12]. In Horeweg et al., the authors evaluated the characteristics of screening-detected LC in the NELSON trial, encouraging a regimen of LC screening of 2 years, with high specificity and 
sensitivity [10]. The detection of pulmonary nodules during screening in asymptomatic patients increases the number of early detected LC, and also the number of undefined lung nodules that require surveillance during the patient's lifetime. A correct screening algorithm and classification of detected nodules are essential, even though the best management protocol to define malignant versus benign lesions remains under debate [31]. MDCT screening represents a path towards the resolution of this issue; however, there are many differences that exist between the guidelines for lung nodule management [19,24-26]. Even though there is substantial concordance in all trials, regarding the management of solid nodules, especially for nodules $<6 \mathrm{~mm}$ that require optional follow-up, greater lesions $(>8 \mathrm{~mm}$ ) should be managed in accordance with the nodule morphology and modifications during the follow-up period, making CT the most suitable surveillance method [24]. In de Koning et al., annual LDCT screening was recommended for people at high risk of LC by the US Preventive Services Task Force and medical societies, according to the American College of Chest Physicians guidelines [13,24]; however, no reduction in LC mortality with the use of the same guidelines has been reported in Infante et al. (2015) [9], possibly due to its smaller sample sizes. For this reason, in 2017, Infante et al. conducted a patient-level pooled analysis of two Italian randomized controlled trials [12]; however, a nonsignificant $(11 \%)$ reduction in overall mortality in individuals undergoing LDCT screening was found. Horewag et al. and Aberle et al. $[10,11]$ adhered to the same guidelines, achieving similar results to de Koning et al., showing a decrease in death rate with the use of LDCT in LC screening [13]. PS and GG nodule management are the most challenging; PS lesions are often pre-malignant or malignant, in accordance with the evolution of the solid component of the nodule, and, for this reason, they require closer surveillance [24] (Figure 2a-f).

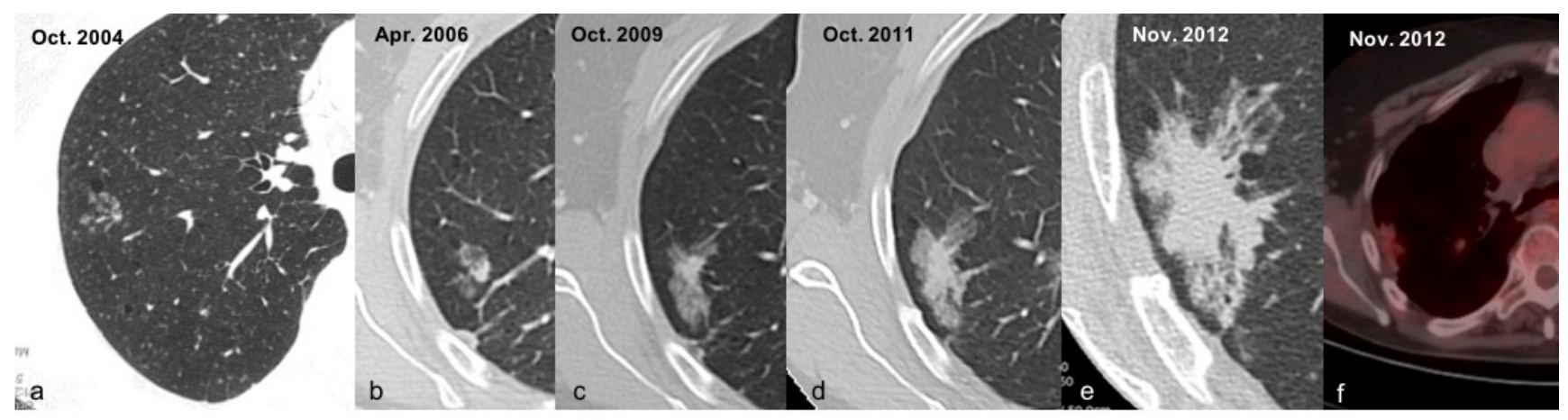

Figure 2. (a-f) This is an example of a PS pre-malignant nodule (a) with evolution in malignant lesion (a-e), confirmed by PET-CT (f), in accordance with changes in the solid component of the nodule.

GG lesions were considered possibly malignant if they were larger than $30 \mathrm{~mm}$, or in the case of persistence during follow-up. The greatest number of GG lesions $<6 \mathrm{~mm}$ tended to disappear by the 6-month follow-up CT examination, due to their inflammatory nature (bronchiolitis, etc.) (Figure 3a,b) [18].

However, nodule measurements can be affected by different biases, related to the irregular shape, closeness to other structures (blood vessels, bronchi, etc.), motion artefacts (related to the patient or due to the proximity with the heart), or superimposed diseases that partially or totally cover the nodule [25]. No considerations were reported about GG or PS lesion detection and characterization in all the evaluated trials.

Concerning technical acquisition protocols, some considerations are necessary. Many studies demonstrate non-significant differences in the variability of the measured nodules between LDCT and standard-dose CT (also not affecting nodule detection) if a maximum section thickness of $1.25 \mathrm{~mm}$ was reported and contiguous section CT images were acquired (evidence level 2+) [32-35]. In the literature search, no study reported any difference between LDCT and standard-dose CT for pure GG nodule characterization; this is because most studies were aimed at nodule detection, even though slice thickness can affect nodule 
morphological evaluation. A thinner acquisition or reconstruction using a high spatial frequency algorithm (bone plus), with $1.25 \mathrm{~mm}$ slice thickness, allows the detection of "signs of malignity" (bronchus sign, pleural tag, and spiculate shape), which are highly suggestive of invasive lesions, regardless of the dimensions and growth timing $[36,37]$ (Figure $4 a-d)$.
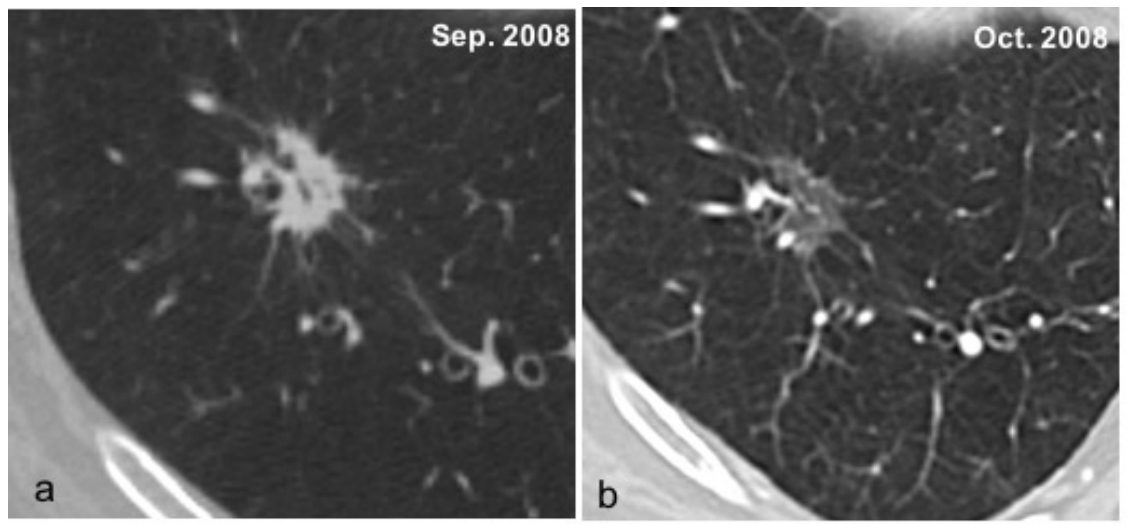

Figure 3. $(\mathbf{a}, \mathbf{b})$ This is an example of a solid nodule (a) suspected for malignant lesion. However, at 1-month follow-up CT examination, it tends to disappear due to its inflammatory nature (b).
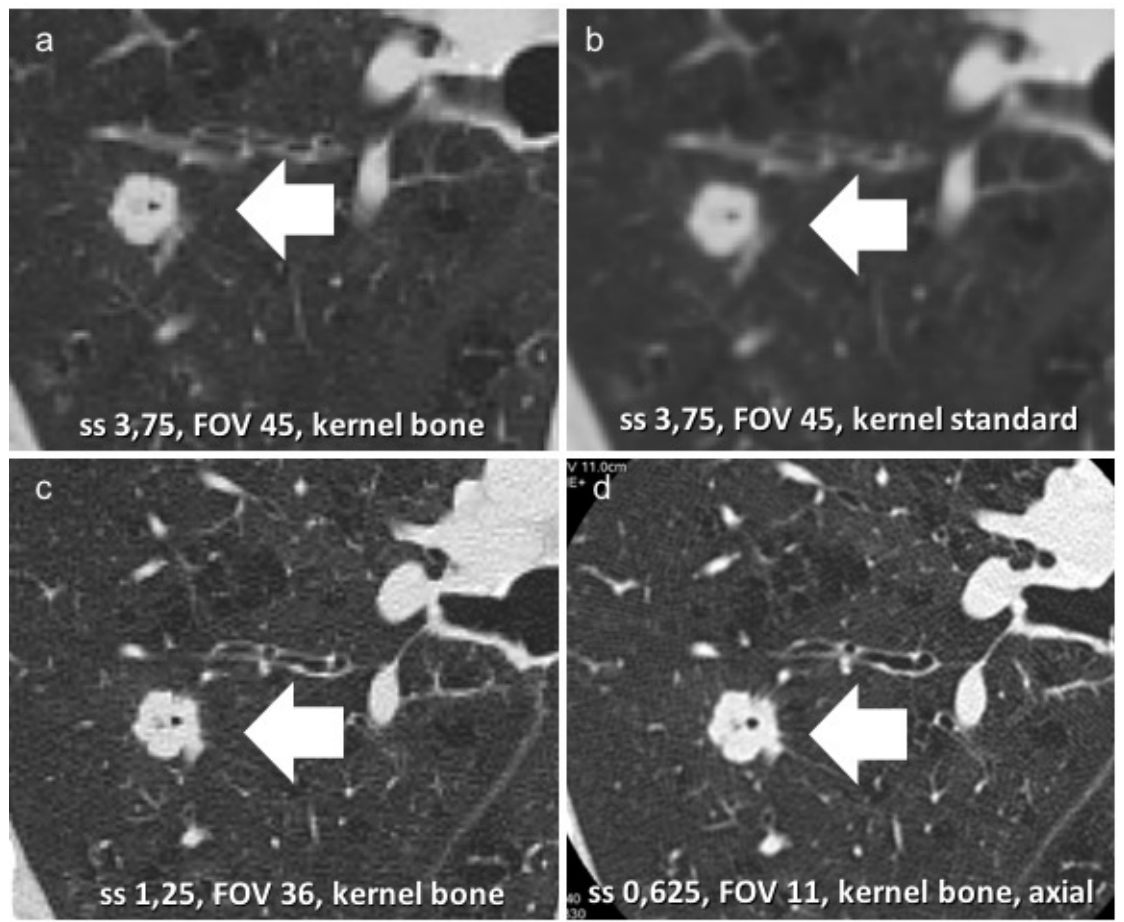

Figure 4. (a-d) This is an example of a solid nodule suspected for malignant lesion (a-d). Reconstruction using a high spatial frequency algorithm (bone plus, $(\mathbf{a}, \mathbf{c}, \mathbf{d})$ ) with a thinner acquisition $(0.625 \mathrm{~mm}$, axial, (d)), which allows the characterization of this malignant lesion.

However, most LDCTs use a section thickness of $2.5 \mathrm{~mm}$ to assess for interval changes in size and density, and to detect and measure solid components, which are sufficient to address nodule management [38]. The volume doubling time (VDT) remains the most attractive option in lung nodule follow-up; however, many issues influence this choice, such as the non-linear growth of some lesions, rapid spread of adenocarcinomas from preinvasive lesions, and the possibility of benign lesions to grow quickly [39-41] (Figure 5a-d). 


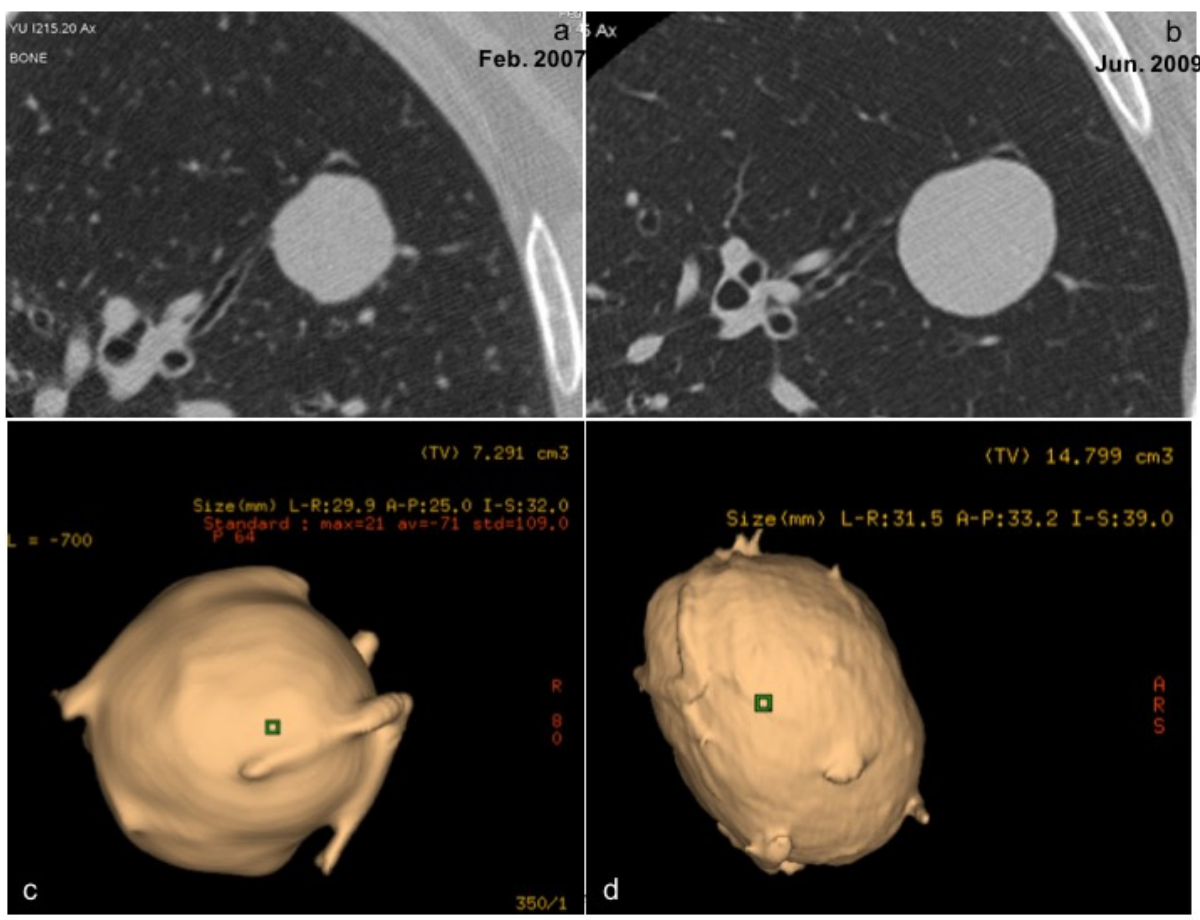

Figure 5. (a-d). This is an example of a solid nodule, amartocondroma $(\mathbf{a}, \mathbf{c})$, with a fast growth (2 years), confirmed with 3D reconstructions $(\mathbf{b}, \mathbf{d})$.

Artificial intelligence (AI) should also be mentioned, which, through automated detection, segmentation, and computer-aided diagnosis (CAD), helps in the identification of suspicious lesions [42]. Radiomics represents a promising AI algorithm, based on the extraction of a data set of features from an image, which allows for the automated classification of medical images. The features evaluated mainly concern nodule shape; however, at the time of writing this paper, more than 100 features have been defined [42-45]. Unfortunately, radiomic signatures are not standardized yet, and the lack of optimal reproducibility makes radiomics impossible to use in screening programs; though, in the future, it may represent a valid tool for LC detection. Similarly, CTp can be used to differentiate benign from malignant lesions throughout the functional imaging information provided by imaging of the first pass of the contrast medium through the interested tissue [46]. In particular, CTp can be used to distinguish LC from inflammatory nodules on the basis of the permeability surface (PS), derived from CTp acquisitions. However, CTp has not been routinely utilized in clinical practice, despite the wide distribution of commercial CTp software [47].

\section{Conclusions}

This systematic review arises from a vast and meticulous research of the literature regarding screening results and lung nodule management. Many articles were published between 2010 and 2020 because the technological evolution and widespread diffusion of MDCT produced rapid changes in lung nodule management. The results highlight the efficacy of the American College of Chest Physicians guidelines for lung nodule management in decreasing the rate of deaths when using LDCT for LC screening. The results remain uncertain regarding long-term follow-up; it is, however, possible that a longer follow-up time (>10 years), especially for pure GG nodules, could lead to advantages that should be further investigated. On the other hand, a unique 3-month follow-up CT scan seems to be effective in assessing the resolution of infected nodules. Future integration and implementation of nodule management protocols is desirable to achieve an improvement in screening for LC, to avoid missed cancers and to reduce the number of unnecessary investigations. 


\begin{abstract}
Author Contributions: Conceptualization, S.G. and M.A.M.; methodology, S.G.; software, M.Z. and P.C.; validation, L.V., M.A.M. and E.B.; formal analysis, M.Z. and P.C.; investigation, D.D.R.; resources, D.D.R.; data curation, S.G., M.Z., L.L.; writing-original draft preparation, S.G. and M.Z.; writing-review and editing, S.G. and M.A.M.; visualization, S.G.; supervision, L.L.; project administration, L.L.; funding acquisition, S.G. All authors have read and agreed to the published version of the manuscript.
\end{abstract}

Funding: This research received no external funding.

Institutional Review Board Statement: Ethical review and approval were waived for this study, because it is a systematic review.

Informed Consent Statement: Patient consent was waived because it is a systematic review.

Acknowledgments: English language editing and proofreading by Martin Vitiello, mother tongue freelance translator. The paper was printed through an educational grant by SIRM Foundation.

Conflicts of Interest: The authors declare no conflict of interest.

\title{
References
}

1. Siegel, R.L.; Miller, K.D.; Jemal, A. Cancer statistics, 2018. CA Cancer J. Clin. 2018, 68, 7-30. [CrossRef] [PubMed]

2. Mazzei, M.A.; Guerrini, S.; Genovese, E.A.; Voltolini, L.; Mazzei, F.G.; Volterrani, L.; Macarini, L. Accuratezza della TC multistrato con approccio multiparametrico nel restaging di pazienti affetti da carcinoma polmonare non a piccole cellule con positività mediastinica sottoposti a chemioterapia neoadiuvante [Accuracy of multislice CT in restaging patients with non-small cell lung carcinoma after neoadjuvant chemotherapy using a multiparametric approach]. Recenti Prog. Med. 2012, 103, 465-470. (In Italian) [CrossRef] [PubMed]

3. Jemal, A.; Center, M.M. Global patterns of cancer incidence and mortality rates and trends. Cancer Epidemiol. Biomark. Prev. 2010, 19, 1893-1907. [CrossRef]

4. Mazzei, M.A.; Contorni, F.; Gentili, F.; Guerrini, S.; Mazzei, F.G.; Pinto, A.; Cioffi Squitieri, N.; Sisinni, A.G.; Paolucci, V.; Romeo, R.; et al. Incidental and Underreported Pleural Plaques at Chest CT: Do Not Miss Them-Asbestos Exposure Still Exists. BioMed Res. Int. 2017, 2017, 6797826. [CrossRef] [PubMed]

5. Volterrani, L.; Guerrini, S.; Zanfrini, E.; Grassi, A.; Addamo, E.; Mathieu, F.; Gentili, F.; Bellan, C.; Spina, D.; Mazzei, M.A.; et al. HRCT predictors of GGO surgical resection: Histopathological and molecular correlation in the era of lung sparing surgery. Lung Cancer 2022. [CrossRef]

6. Paolucci, V.; Romeo, R.; Sisinni, A.G.; Scancarello, G.; Volterrani, L.; Mazzei, M.A.; Barabesi, L.; Sartorelli, P. Asbestos exposure biomarkers in the follow-up of asbestos-exposed workers. Ind. Health 2018, 56, 249-254. [CrossRef]

7. Mazzei, M.A.; Sartorelli, P.; Bagnacci, G.; Gentili, F.; Sisinni, A.G.; Fausto, A.; Mazzei, F.G.; Volterrani, L. Occupational Lung Diseases: Underreported Diagnosis in Radiological Practice. Semin. Ultrasound CT MR 2019, 40, 36-50. [CrossRef]

8. Saghir, Z.; Dirksen, A.; Ashraf, H.; Bach, K.S.; Brodersen, J.; Clementsen, P.F.; Døssing, M.; Hansen, H.; Kofoed, K.F.; Larsen, K.R.; et al. CT screening for lung cancer brings forward early disease. The randomised Danish Lung Cancer Screening Trial: Status after five annual screening rounds with low-dose CT. Thorax 2012, 67, 296-301. [CrossRef]

9. Infante, M.; Cavuto, S.; Lutman, F.R.; Passera, E.; Chiarenza, M.; Chiesa, G.; Brambilla, G.; Angeli, E.; Aranzulla, G.; Chiti, A.; et al. Long-Term Follow-up Results of the DANTE Trial, a Randomized Study of Lung Cancer Screening with Spiral Computed Tomography. Am. J. Respir. Crit. Care Med. 2015, 191, 1166-1175. [CrossRef]

10. Horeweg, N.; Scholten, E.T.; de Jong, P.A.; van der Aalst, C.M.; Weenink, C.; Lammers, J.W.; Nackaerts, K.; Vliegenthart, R.; ten Haaf, K.; Yousaf-Khan, U.A.; et al. Detection of lung cancer through low-dose CT screening (NELSON): A prespecified analysis of screening test performance and interval cancers. Lancet Oncol. 2014, 15, 1342-1350. [CrossRef]

11. National Lung Screening Trial Research Team; Aberle, D.R.; Adams, A.M.; Berg, C.D.; Black, W.C.; Clapp, J.D.; Fagerstrom, R.M.; Gareen, I.F.; Gatsonis, C.; Marcus, P.M.; et al. Reduced lung-cancer mortality with low-dose computed tomographic screening. N. Engl. J. Med. 2011, 365, 395-409. [CrossRef] [PubMed]

12. Infante, M.; Sestini, S.; Galeone, C.; Marchianò, A.; Lutman, F.R.; Angeli, E.; Calareso, G.; Pelosi, G.; Sozzi, G.; Silva, M.; et al. Lung cancer screening with low-dose spiral computed tomography: Evidence from a pooled analysis of two Italian randomized trials. Eur. J. Cancer Prev. 2017, 26, 324-329. [CrossRef] [PubMed]

13. De Koning, H.J.; van der Aalst, C.M.; de Jong, P.A.; Scholten, E.T.; Nackaerts, K.; Heuvelmans, M.A.; Lammers, J.J.; Weenink, C.; Yousaf-Khan, U.; Horeweg, N.; et al. Reduced Lung-Cancer Mortality with Volume CT Screening in a Randomized Trial. N. Engl. J. Med. 2020, 382, 503-513. [CrossRef]

14. Xu, D.M.; Gietema, H.; de Koning, H.; Vernhout, R.; Nackaerts, K.; Prokop, M.; Weenink, C.; Lammers, J.W.; Groen, H.; Oudkerk, M.; et al. Nodule management protocol of the NELSON randomised lung cancer screening trial. Lung Cancer 2006, 54, 177-184. [CrossRef] 
15. Mazzei, F.G.; Volterrani, L.; Guerrini, S.; Cioffi Squitieri, N.; Sani, E.; Bettini, G.; Pozzessere, C.; Mazzei, M. Reduced time CT perfusion acquisitions are sufficient to measure the permeability surface area product with a deconvolution method. BioMed Res. Int. 2014, 2014, 573268. [CrossRef]

16. Mazzei, M.A.; Cioffi Squitieri, N.; Guerrini, S.; Di Crescenzo, V.; Rossi, M.; Fonio, P.; Mazzei, F.G.; Volterrani, L. La perfusione con TC nella caratterizzazione del nodulo polmonare solitario: Possibilità e limiti in uno studio preliminare [Quantitative CT perfusion measurements in characterization of solitary pulmonary nodules: New insights and limitations]. Recenti Prog. Med. 2013, 104, 430-437. (In Italian) [CrossRef]

17. Mazzei, M.A.; Squitieri, N.C.; Sani, E.; Guerrini, S.; Imbriaco, G.; Di Lucia, D.; Guasti, A.; Mazzei, F.G.; Volterrani, L. Differences in perfusion CT parameter values with commercial software upgrades: A preliminary report about algorithm consistency and stability. Acta Radiol. 2013, 54, 805-811. [CrossRef]

18. Cicero, G.; Ascenti, G.; Albrecht, M.H.; Blandino, A.; Cavallaro, M.; D'Angelo, T.; Carerj, M.L.; Vogl, T.J.; Mazziotti, S. Extraabdominal dual-energy CT applications: A comprehensive overview. Radiol. Med. 2020, 125, 384-397. [CrossRef]

19. MacMahon, H.; Naidich, D.P.; Goo, J.M.; Lee, K.S.; Leung, A.; Mayo, J.R.; Mehta, A.C.; Ohno, Y.; Powell, C.A.; Prokop, M.; et al. Guidelines for Management of Incidental Pulmonary Nodules Detected on CT Images: From the Fleischner Society 2017. Radiology 2017, 284, 228-243. [CrossRef]

20. Digumarthy, S.R.; Mendoza, D.P.; Lin, J.J.; Chen, T.; Rooney, M.M.; Chin, E.; Sequist, L.V.; Lennerz, J.K.; Gainor, J.F.; Shaw, A.T.; et al. Computed Tomography Imaging Features and Distribution of Metastases in ROS1-rearranged Non-Small-cell Lung Cancer. Clin. Lung Cancer 2020, 21, 153-159. [CrossRef]

21. Mendoza, D.P.; Heeger, A.; Mino-Kenudson, M.; Lanuti, M.; Shepard, J.A.; Sequist, L.V.; Digumarthy, S.R. Clinicopathologic and Longitudinal Imaging Features of Lung Cancer Associated with Cystic Airspaces: A Systematic Review and Meta-Analysis. AJR Am. J. Roentgenol. 2021, 216, 318-329. [CrossRef] [PubMed]

22. Jett, J.R. Limitations of screening for lung cancer with low-dose spiral computed tomography. Clin. Cancer Res. 2005, 11, 4988s-4992s. [CrossRef] [PubMed]

23. Volterrani, L.; Mazzei, M.A.; Banchi, B.; Voltolini, L.; La Sala, F.; Carbone, S.F.; Ricci, V.; Gotti, G.; Zompatori, M. MSCT multicriteria: A novel approach in assessment of mediastinal lymph node metastases in non-small cell lung cancer. Eur. J. Radiol. 2011, 79, 459-466. [CrossRef] [PubMed]

24. Gould, M.K.; Donington, J.; Lynch, W.R.; Mazzone, P.J.; Midthun, D.E.; Naidich, D.P.; Wiener, R. Evaluation of individuals with pulmonary nodules: When is it lung cancer? Diagnosis and management of lung cancer, 3rd ed: American College of Chest Physicians evidence-based clinical practice guidelines. Chest 2013, 143, e93S-e120S. [CrossRef] [PubMed]

25. Callister, M.E.; Baldwin, D.R.; Akram, A.R.; Barnard, S.; Cane, P.; Draffan, J.; Franks, K.; Gleeson, F.; Graham, R.; Malhotra, P.; et al. British Thoracic Society Pulmonary Nodule Guideline Development Group; British Thoracic Society Standards of Care Committee. British Thoracic Society guidelines for the investigation and management of pulmonary nodules. Thorax 2015, 70, ii1-ii54; Erratum in Thorax 2015, 70, 1188. [CrossRef] [PubMed]

26. American College of Radiology. Lung CT Screening Reporting and Data System (Lung-RADS). Available online: www.acr.org/ Clinical-Resources/Reporting-and-Data-Systems/Lung-Rads (accessed on 13 April 2020).

27. Mazzone, P.J.; Gould, M.K.; Arenberg, D.A.; Chen, A.C.; Choi, H.K.; Detterbeck, F.C.; Farjah, F.; Fong, K.M.; Iaccarino, J.M.; Janes, S.M.; et al. Management of Lung Nodules and Lung Cancer Screening During the COVID-19 Pandemic: CHEST Expert Panel Report. Radiol. Imaging Cancer 2020, 2, e204013. [CrossRef]

28. Pedersen, J.H.; Ashraf, H.; Dirksen, A.; Bach, K.; Hansen, H.; Toennesen, P.; Thorsen, H.; Brodersen, J.; Skov, B.G.; Døssing, M.; et al. The Danish randomized lung cancer CT screening trial-overall design and results of the prevalence round. J. Thorac. Oncol. 2009, 4, 608-614. [CrossRef]

29. Becker, N.; Motsch, E.; Gross, M.L.; Eigentopf, A.; Heussel, C.P.; Dienemann, H.; Schnabel, P.A.; Pilz, L.; Eichinger, M.; Optazaite, D.E.; et al. Randomized study on early detection of lung cancer with MSCT in Germany: Study design and results of the first screening round. J. Cancer Res. Clin. Oncol. 2012, 138, 1475-1486. [CrossRef]

30. Lopes Pegna, A.; Picozzi, G.; Mascalchi, M.; Maria Carozzi, F.; Carrozzi, L.; Comin, C.; Spinelli, C.; Falaschi, F.; Grazzini, M.; Innocenti, F.; et al. ITALUNG Study Research Grou. Design, recruitment and baseline results of the ITALUNG trial for lung cancer screening with low-dose CT. Lung Cancer 2009, 64, 34-40. [CrossRef]

31. Franceschini, D.; Bruni, A.; Borghetti, P.; Giaj-Levra, N.; Ramella, S.; Buffoni, L.; Badellino, S.; Andolina, M.; Comin, C.; Vattemi, E.; et al. Is multidisciplinary management possible in the treatment of lung cancer? A report from three Italian meetings. Radiol. Med. 2020, 125, 214-219. [CrossRef]

32. Hein, P.A.; Romano, V.C.; Rogalla, P.; Klessen, C.; Lembcke, A.; Bornemann, L.; Dicken, V.; Hamm, B.; Bauknecht, H.C. Variability of semiautomated lung nodule volumetry on ultralow-dose CT: Comparison with nodule volumetry on standard-dose CT. $J$. Digit. Imaging 2010, 23, 8-17. [CrossRef] [PubMed]

33. Christe, A.; Torrente, J.C.; Lin, M.; Yen, A.; Hallett, R.; Roychoudhury, K.; Schmitzberger, F.; Vock, P.; Roos, J. CT screening and follow-up of lung nodules: Effects of tube current-time setting and nodule size and density on detectability and of tube current-time setting on apparent size. AJR Am. J. Roentgenol. 2011, 197, 623-630. [CrossRef] [PubMed]

34. Gartenschläger, M.; Schweden, F.; Gast, K.; Westermeier, T.; Kauczor, H.; von Zitzewitz, H.; Thelen, M. Pulmonary nodules: Detection with low-dose vs conventional-dose spiral CT. Eur. Radiol. 1998, 8, 609-614. [CrossRef] 
35. Karabulut, N.; Törü, M.; Gelebek, V.; Gülsün, M.; Ariyürek, O.M. Comparison of low-dose and standard-dose helical CT in the evaluation of pulmonary nodules. Eur. Radiol. 2002, 12, 2764-2769. [CrossRef] [PubMed]

36. Kim, J.; Dabiri, B.; Hammer, M.M. Micronodular lung disease on high-resolution CT: Patterns and differential diagnosis. Clin. Radiol. 2021, 76, 399-406. [CrossRef]

37. Abbritti, M.; Mazzei, M.A.; Bargagli, E.; Refini, R.M.; Penza, F.; Perari, M.G.; Volterrani, L.; Rottoli, P. Utility of spiral CAT scan in the follow-up of patients with pulmonary Langerhans cell histiocytosis. Eur. J. Radiol. 2012, 81, 1907-1912. [CrossRef]

38. Godoy, M.C.; Naidich, D.P. Overview and strategic management of subsolid pulmonary nodules. J. Thorac. Imaging 2012, 27, 240-248. [CrossRef]

39. Thunnissen, F.B.; Schuurbiers, O.C.; den Bakker, M.A. A critical appraisal of prognostic and predictive factors for common lung cancers. Histopathology 2006, 48, 779-786. [CrossRef]

40. Volterrani, L.; Mazzei, M.A.; Scialpi, M.; Carcano, M.; Carbone, S.F.; Ricci, V.; Guazzi, G.; Lupattelli, L. Three-dimensional analysis of pulmonary nodules by MSCT with Advanced Lung Analysis (ALA1) software. Radiol. Med. 2006, 111, 343-354. [CrossRef]

41. Mazzei, M.A.; Scialpi, M.; Mazzei, F.G.; Giacobone, G.; Volterrani, L. Three-dimensional volumetric assessment with thoracic CT: A reliable approach for noncalcified lung nodules? Radiology 2010, 254, 634. [CrossRef]

42. Binczyk, F.; Prazuch, W.; Bozek, P.; Polanska, J. Radiomics and artificial intelligence in lung cancer screening. Transl. Lung Cancer Res. 2021, 10, 1186-1199. [CrossRef] [PubMed]

43. Fusco, R.; Granata, V.; Mazzei, M.A.; Meglio, N.D.; Roscio, D.D.; Moroni, C.; Monti, R.; Cappabianca, C.; Picone, C.; Neri, E.; et al. Quantitative imaging decision support (QIDS ${ }^{\mathrm{TM}}$ ) tool consistency evaluation and radiomic analysis by means of 594 metrics in lung carcinoma on chest CT scan. Cancer Control 2021, 28, 1073274820985786. [CrossRef] [PubMed]

44. Nardone, V.; Tini, P.; Pastina, P.; Botta, C.; Reginelli, A.; Carbone, S.F.; Giannicola, R.; Calabrese, G.; Tebala, C.; Guida, C.; et al. Radiomics predicts survival of patients with advanced non-small cell lung cancer undergoing PD-1 blockade using Nivolumab. Oncol. Lett. 2020, 19, 1559-1566. [CrossRef] [PubMed]

45. Zhang, G.; Yang, Z.; Gong, L.; Jiang, S.; Wang, L.; Zhang, H. Classification of lung nodules based on CT images using squeezeand-excitation network and aggregated residual transformations. Radiol. Med. 2020, 125, 374-383. [CrossRef]

46. Volterrani, L.; Mazzei, M.A.; Fedi, M.; Scialpi, M. Computed tomography perfusion using first pass methods for lung nodule characterization: Limits and implications in radiologic practice. Invest. Radiol. 2009, 44, 124. [CrossRef]

47. Mazzei, M.A.; Preda, L.; Cianfoni, A.; Volterrani, L. CT perfusion: Technical developments and current and future applications. BioMed Res. Int. 2015, 2015, 397521. [CrossRef] 